\title{
Chiral Arenethiolatocopper(I) Catalyzed Substitution Reactions of Acyclic Allylic Substrates with Grignard Reagents.
}

\author{
Mayra van Klaveren, ${ }^{\dagger}$ Eva S. M. Persson, ${ }^{\ddagger}$ Amaya del Villar, ${ }^{\dagger}$ David M. Grove, ${ }^{\dagger}$ \\ Jan-E BäckvalI ${ }^{\ddagger}, *$ and Gerard van Koten ${ }^{\dagger, *}$ \\ ${ }^{\dagger}$ Debye Institute, Department of Metal-Mediated Synthesis, Utrecht University, \\ Padualaan 8, $3584 \mathrm{CH}$ Utrecht, The Netherlands \\ and

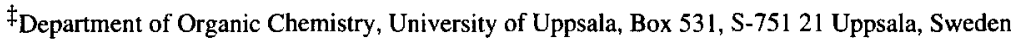

\begin{abstract}
Asymmetric induction can be achieved in the $\gamma$-selective substitution reaction of allylic substrates ( $\mathrm{R}^{\prime} \mathrm{CH}=\mathrm{CH}-\mathrm{CH}_{2} \mathrm{Y}$ ) with $n$-BuMgI catalyzed by the chiral arenethiolatocopper(I) complex $1 \mathrm{~b}$. It was found that the enantiomeric excess of the $\gamma$-substituted product $\left(\mathrm{R}^{\prime} \mathrm{CH}(n-\mathrm{Bu}) \mathrm{CH}=\mathrm{CH}_{2}\right)$ is influenced by the coordinating ability of the leaving group $\mathrm{Y}$, and e.e.'s of up to $42 \%\left(\mathrm{R}^{\prime}=\mathrm{Cy}, \mathrm{Y}=\mathrm{OAc}\right)$ have been obtained.
\end{abstract}

The copper(I)-catalyzed cross-coupling reaction of organometallic reagents with allylic substrates is an important reaction for carbon-carbon bond formation, and several catalytic systems have been developed for the control of regio- and stereoselectivity in this reaction. ${ }^{1-3}$

The arenethiolatocopper(I) complexes 1, realized by van Koten et al. ${ }^{4}$ have been shown to be excellent catalysts for selective copper-catalyzed allylic substitution reactions. ${ }^{5}$ Depending on the reaction conditions used, the regioselectivity could be directed to afford either the $\alpha$ - or $\gamma$-substituted product (Scheme 1). In these reactions the arenethiolate ligand of $\mathbf{1}$ functions as an excellent non-transferable group and catalysts 1 have also successfully been used in 1,4-addition reactions with enones ${ }^{6 a}$ and 1,6 -addition reactions with enynes. ${ }^{6 b}$

\section{Scheme 1}<smiles>CC(=O)OCC=C(C)CCC=C(C)C</smiles>

geranyl acetate

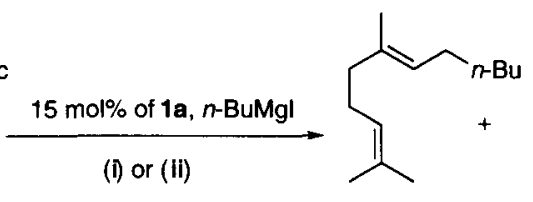

$\alpha$-product<smiles>C=CC(C)(CCC=C(C)C)CCCCC</smiles>

$\gamma$-product

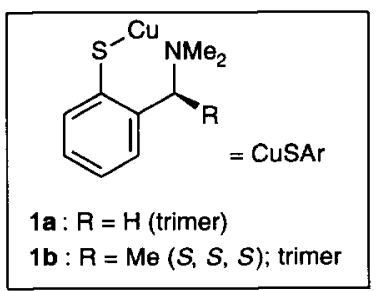

(i) $\mathrm{Et}_{2} \mathrm{O}, 0{ }^{\circ} \mathrm{C}, 120$ min addition time: $100 \% \gamma$-product

(ii) THF, $-30^{\circ} \mathrm{C}, 5$ min addition time: $100 \% \alpha$-product 
In this communication, we report that asymmetric induction can be achieved in the $\gamma$-selective reaction between acyclic allylic substrates $\mathrm{R}^{\prime} \mathrm{CH}=\mathrm{CHCH}_{2} \mathrm{Y}(\mathbf{2 a - d}, \mathbf{3 a})$ and $n$ - $\mathrm{BuMgI}$ using the chiral arenethiolatocopper(I) complex $1 \mathrm{~b}$ (prepared from $L(-)-\alpha-$-methyl benzylamine with an e.e. $>99.8 \%$ ). ${ }^{4 \mathrm{c}}$ The coordinating ability of the leaving group $\mathrm{Y}$ in the allylic substrate is shown to be an important factor in determining the enantioselectivity of this reaction.

The current study pertains to the influence of (i) the leaving group $Y$, (ii) the substituent $R$ ', (iii) the addition method and (iv) the temperature on the regio- and enantioselectivity of this reaction (Scheme 2). The results are collected in Table I. Generally, $n$-BuMgI (1.25 equiv) is added within $120 \mathrm{~min}$ to a solution of 5 $15 \mathrm{~mol} \%$ of $1 \mathrm{~b}$ (based on monomeric copper units) and the substrate 2 or 3 (1 equiv) in $\mathrm{Et}_{2} \mathrm{O}$ at $0^{\circ} \mathrm{C}$ (addition method A). ${ }^{5}$

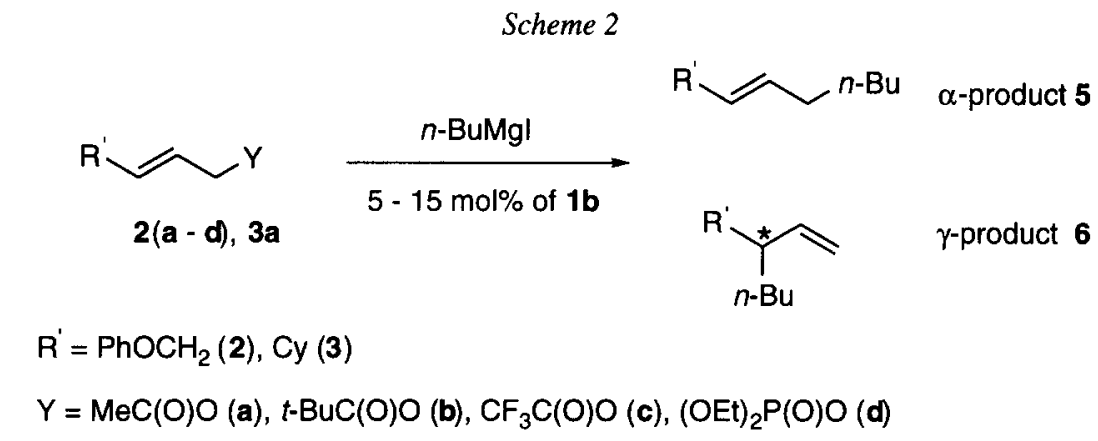

(i) The leaving group $Y$. With both the allylic acetate $2 \mathbf{a}$ and the allylic pivalate $2 \mathbf{b}$ the reaction affords the $\gamma$-product 6 in high regioselectivity ( $c f$, entries 1 and 2). The $\gamma$-product formed from allylic acetate $2 a$ (entry 1) has an e.e. of $34 \%$, whereas that formed from the bulkier allylic pivalate $\mathbf{2 b}$ has a slightly lower e.e. of $25 \%$ (entry 2). The cross-coupling reactions with the allylic trifluoroacetate $2 \mathrm{c}$ (entry 3 ) and allylic phosphate $\mathbf{2 d}$ (entry 4 ) proceed with lower enantioselectivity than the reaction with allylic acetate $\mathbf{2 a}$. Furthermore, the regioselectivity of the reaction of $2 \mathbf{c}$ and $\mathbf{2 d}$ is slightly lower than that of the reaction of $2 \mathbf{a}$.

(ii) The substituent $\mathbf{R}^{\prime}$. The terminal $\mathbf{R}^{\prime}$ substituent of the alkene double bond has no significant influence on the regioselectivity of the reaction and substrates $2 \mathrm{a}$ and 3a both give $100 \% \gamma$-substitution. These substrates also result in $\gamma$-products with a similar enantiomeric excess of about $35 \%$ (entries 1 and 5 ) with method A.

(iii) The addition method. The e.e. of the $\gamma$-substituted product 6 can be influenced by a change in the addition method. For example, when method $\mathrm{A}$ is used (vide supra) with allylic substrate $3 \mathrm{a}$ the $\gamma$-product has an e.e. of $34 \%$ (entry 5). However, when the Grignard reagent $n$-BuMgI and $\mathbf{3 a}$ are added separately at the same rate to a solution of the catalyst $1 \mathrm{~b}(15 \mathrm{~mol} \%)$ a higher e.e. of $42 \%$ is obtained (entry 6$)$.

(iv) Temperature effects. The cross-coupling reactions of $n$-BuMgI with 3a catalyzed by $5 \mathrm{~mol} \%$ of $\mathbf{1 b}$ carried out at $0{ }^{\circ} \mathrm{C}$ and at the higher temperature of $20^{\circ} \mathrm{C}$ have similar enantioselectivities with the $\gamma$-products having e.e.'s of $29 \%$ and $31 \%$, respectively ( $c f$. entries 7 and 8 ). However, lowering the temperature to $-20^{\circ} \mathrm{C}$ decreases the enantioselectivity of the reaction and the $\gamma$-product is obtained with an e.e. of $7 \%$ (entry 9 ). 
Table I. Cross-coupling reaction of $\mathbf{2}$ and $\mathbf{3}$ with $\boldsymbol{n}$-BuMgI using CuSAr $\mathbf{1 b}$.

\begin{tabular}{|c|c|c|c|c|c|c|c|c|c|}
\hline Entry & $\begin{array}{c}\begin{array}{c}\text { allylic } \\
\text { substrate }\end{array} \\
\end{array}$ & $\mathrm{Y}$ & $\frac{\text { Conditions }}{\left[\text { method, }{ }^{\circ} \mathrm{C}\right]}$ & $\begin{array}{l}\frac{\mathrm{CuSAr}}{\mathrm{b}}_{1 \mathrm{~b}} \\
(\mathrm{~mol} \%)\end{array}$ & $\begin{array}{c}\text { Conversion }^{\mathrm{c}} \\
(2,3) \\
(\%)\end{array}$ & $\begin{array}{c}\underbrace{\text { Yield }^{c}} \\
(5+6) \\
(\%)\end{array}$ & $\frac{\alpha: \gamma_{\text {ratio }}}{(5: 6)}$ & $\begin{array}{l}E_{1, e^{e}} \\
\text { of } 6 \\
(\%)\end{array}$ & $\begin{array}{l}{[\alpha]_{D}} \\
\text { of } 6 \\
\left(^{\circ}\right)\end{array}$ \\
\hline 1. & $\mathbf{2 a}$ & $\mathrm{MeC}(\mathrm{O}) \mathrm{O}$ & {$[A, 0]$} & 13 & 100 & 100 & $0: 100$ & 34 & n. det. \\
\hline 2. & $2 \mathbf{b}$ & $t-\mathrm{BuC}(\mathrm{O}) \mathrm{O}$ & $"$ & 15 & 100 & 100 & $0: 100$ & 25 & n. det. \\
\hline 3. & $2 c$ & $\mathrm{CF}_{3} \mathrm{C}(\mathrm{O}) \mathrm{O}$ & $"$ & 15 & 97 & $81^{f}$ & $10: 90$ & 9 & n. det. \\
\hline 4. & $2 d$ & $(\mathrm{OEt})_{2} \mathrm{P}(\mathrm{O}) \mathrm{O}$ & $"$ & 15 & 100 & 100 & $8: 92$ & 10 & n. det. \\
\hline 5. & $3 \mathbf{a}$ & $\mathrm{MeC}(\mathrm{O}) \mathrm{O}$ & {$[A, 0]$} & 15 & 100 & 100 & $0: 100$ & 35 & +3.70 \\
\hline 6. & $"$ & $"$ & {$[\mathrm{~B}, 0]$} & 14 & 100 & 100 & $0: 100$ & 42 & +4.39 \\
\hline 7. & $\mathbf{3 a}$ & $\mathrm{MeC}(\mathrm{O}) \mathrm{O}$ & {$[A, 20]$} & 5 & 100 & 100 & $0: 100$ & 31 & +3.28 \\
\hline 8. & $"$ & $"$ & {$[A, 0]$} & 5 & 100 & 100 & $0: 100$ & 29 & +3.10 \\
\hline 9. & $"$ & $"$ & {$[A,-20]$} & 5 & 89 & 89 & $0: 100$ & 7 & +0.78 \\
\hline
\end{tabular}

a) Method $\mathrm{A}$ : $n$-BuMgI (1.25 equiv) is added within 120 min to a solution of $\mathbf{1 b}$ and substrate (1 equiv) in $\mathrm{Et}_{2} \mathrm{O}$. Method $\mathrm{B}: n$ BuMgI (1 equiv) in $50 \mathrm{~mL}$ of $\mathrm{Et}_{2} \mathrm{O}$ and substrate (1 equiv) in $50 \mathrm{~mL}$ of $\mathrm{Et}_{2} \mathrm{O}$ are added separately at the same time to a solution of $1 \mathbf{b}$ in $30 \mathrm{~mL}$ of toluene. b) Based on monomeric copper units. c) Entries 1-4: Conversion and yield determined by GC with the internal standard $n$-dodecane; entries 5-9: Conversion and yield determined by GC and ${ }^{1} \mathbf{H}$ NMR. d) Determined by GC. e) In the case of products formed from 2 the e.e. is determined by HPLC using a chiracel OD-H column; in the case of products formed from 3 the e.e. is determined by optical rotation $\left([\alpha]_{\mathrm{D}}=-9.4\right.$ corresponds to $88 \%$ e.e. of $R$-enantiomer). ${ }^{9} \mathrm{f}$ ) side products (identified by GC-MS) are $\mathrm{PhOH},(n-\mathrm{Bu}) \mathrm{CH}_{2} \mathrm{CH}=\mathrm{CH}-\mathrm{CH}_{2} \mathrm{OC}(\mathrm{O}) \mathrm{CF}_{3}$ and $\mathrm{PhOCH}_{2} \mathrm{CH}=\mathrm{CH}-\mathrm{CH}_{2} \mathrm{OH}$.

In previous reports we have proposed that the allylic acetate $2 \mathrm{a}(\mathrm{Y}=\mathrm{MeC}(\mathrm{O}) \mathrm{O})$ anchors in a bidentate fashion to the $\mathrm{Cu}$-SAr-Mg moiety in such a way that there is a copper-alkene $\pi$-interaction and coordination of the carbonyl oxygen atom to the $\mathrm{Mg}$ atom (Intermediate $\mathrm{I}$ ). ${ }^{5}$ This bidentate coordination results in an enhanced reactivity of the leaving group and this leads to preferential $\gamma$-substitution. Furthermore, it seems that the efficacy of chelation by the allylic substrate is also important in determining the enantioselectivity of the substitution reaction. The slight decrease in the e.e. of the $\gamma$-product derived from pivalate $\mathbf{2 b}$ compared with that derived from acetate 2a can be explained by increased steric bulk of the pivalate reducing the stability of intermediate $\mathbf{I}$. The lower e.e. of the $\gamma$-product obtained from the allylic trifluoroacetate $2 \mathbf{c}$ can be explained by (i) the lower coordinating ability of the carbonyl oxygen (due to the presence of the electronwithdrawing $\mathrm{CF}_{3}$ group) and (ii) the high reactivity of the $\mathrm{CF}_{3} \mathrm{C}(\mathrm{O}) \mathrm{O}$ as leaving group. ${ }^{7}$ Both of these factors will effect the bidentate coordination mode. Similar reasoning explains the low e.e. of the $\gamma$-product derived from the allylic phosphate $\mathbf{2 d}$. $^{8}$

Results from the two addition methods show that a better enantioselectivity is obtained with a $1: 1$ ratio of $n$-BuMgI to allylic substrate (method B). In method A there is an excess of substrate that appears to disrupt to a small extent the bidentate coordination present in intermediate $\mathbf{I}$. The substituent $\mathrm{R}^{\prime}$ ( $\mathrm{PhOCH}_{2}$ and $\mathrm{Cy}$ ) does not lead to different reaction enantioselectivities because the preference for formation (and stability) of intermedate I will, as expected, be similar for these two terminal groups. The decrease in e.e. of the $\gamma$-product when performing the reaction at lower temperature is in accordance with a mechanism in which chelate formation is of importance for the asymmetric induction.

Denmark et al. obtained enantioselectivities of up to $95 \%$ e.e. in the cross-coupling reaction of a chiral allylic carbamate with a stoichiometric amount of an organocopper complex $\mathrm{RCu} .{ }^{9}$ In the present work a 
catalytic amount of the chiral arenethiolatocopper(I) complex $\mathbf{1 b}$ was used and, to the best of our knowledge, this is the first report of a chiral copper(I) complex being used as a catalyst in the cross-coupling reaction of Grignard reagents with allylic substrates.

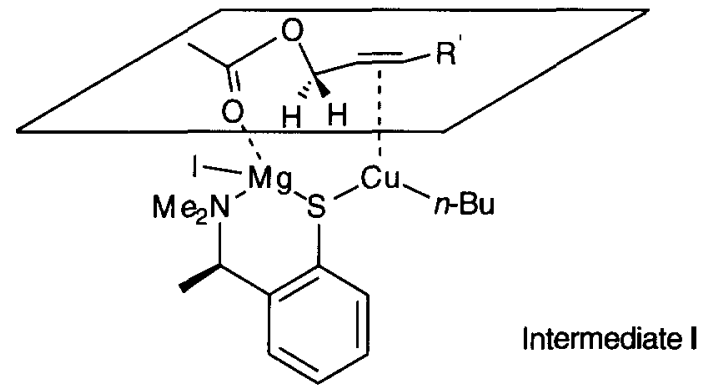

Acknowledgement: This work was supported by the Netherlands Foundation of Chemical Research (SON) with financial aid from the Netherlands Organization for Scientific Research (NWO) and the Swedish Natural Science Research Council.

\section{References and Notes:}

1. a) Magid, R. M. Tetrahedron 1980, 36, 1901. b) Marshall, J. A. Chem. Rev. 1989, 89, 1503. c) Goering, H. L.; Underiner, T. L. J. Org. Chem. 1991, 56, 2563 and earlier work. d) Lipshutz, B. H.; Sengupta, S. Org. React. 1992, 41, 135.

2. a) Bäckvall, J. E.; Sellén, M.; Grant, B. J. Am. Chem. Soc. 1990, 112, 6615. b) Bäckvall, J. E.; Persson, E. S. M.; Bombrun, A. J. Org. Chem. 1994, 59, 4126.

3. a) Fouquet, G.; Schlosser, M. Angew. Chem., Int. Ed. Engl. 1974, 13, 82. b) Levisalles, J.; RudlerChauvin, M.; Rudler, H. J. Organomet. Chem. 1977, 136, 103. c) Gallina, C.; Ciattini, P. G. J. Am. Chem. Soc. 1979, 101, 1035. d) Goering, H. L.; Singleton Jr., V. D. J. Org. Chem. 1983, 48, 1531. e) Goering, H. L.; Kantner, S. S. J. Org. Chem. 1984, 49, 422. f) Goering, H. L.; Kantner, S. S.; Seitz Jr., E. P. J. Org. Chem. 1985, 50, 5485. g) Tseng, C. C.; Paisley, S. D.; Goering, H. L. J. Org. Chem. 1986, 51, 2884. h) Yanagisawa, A.; Noritake, Y.; Nomura, N.; Yamamoto, H. Synlett 1991, 251. i) Yanagisawa, A.; Nomura, N.; Yamamoto, H. Synlett 1993, 251.

4. a) Knotter, D. M.; van Koten, G., van Maanen, H. M.; Grove, D. M.; Spek, A. L. Angew. Chem., Int. Ed. Engl. 1989, 101, 341. b) Knotter, D. M.; van Maanen, H. M.; Grove, D. M.; Spek, A. L.; van Koten, G. Inorg. Chem. 1991, 30, 3309. c) Knotter, D. M.; Janssen, M. D.; Grove, D. M.; Smeets, W. J. J.; Horn, E., Spek, A. L.; van Koten, G. Inorg. Chem. 1991, 30, 4361.

5. a) van Klaveren, M.; Persson, E. S. M.; Grove, D. M.; Bäckvall, J. E.; van Koten, G. Tetrahedron Lett. 1994, 35, 5931. b) Persson, E. S. M.; van Klaveren, M.; Grove, D. M.; Bäckvall, J. E.; van Koten, G. submitted to Chemistry, a European Journal.

6. a) van Klaveren, M.; Lambert, F.; Eijkelkamp, D. J. F. M.; Grove, D. M.; van Koten, G. Tetrahedron Lett. 1994, 35, 6135. b) Haubrich, A.; van Klaveren, M.; van Koten, G.; Handke, G.; Krause, N.; $J$. Org. Chem. 1993, 58, 5849.

7. a) RajanBabu, T. V.J. Org. Chem. 1985, 50, 3642. b) Bäckvall, J. E.; Granberg, K. L.; Heumnann, A. Israel J. Chem. 1991, 31, 17.

8. a) Tanigawa, Y.; Nishimura, K.; Kawasaki, A.; Murahashi, S. I. Tetrahedron Lett. 1982, 23, 5549. b) Genet, J. P.; Balabane, T. M.; Bäckvall, J. E.; Nyström, J. E. Tetrahedron Lett. 1983, $27,2745$.

9. Denmark, S. E.; Marble, L. K. J. Org. Chem. 1990, 55, 1984. 